\title{
A New Hybrid Synchronous Reluctance Machine Capable of Ultra-High Output Power
}

\author{
S E Abonyi \\ Department of Mechanical, Nnamdi Azikiwe University, Awka, Anambra, Nigeria
}

\section{ABSTRACT}

A new hybrid synchronous reluctance machine capable of ultra-high $X_{d} / X_{q}$ ratio output power has been studied. A d-q model (voltage and flux linkage) of the hybrid synchronous reluctance machine has been idealized and developed. Also the impedance and current loci from steady state analysis of the machine was obtained. The effect of capacitor loading in the auxiliary winding was investigated. The power factor and torque developed in the hybrid synchronous reluctance machine was compared with the conventional synchronous reluctance machine. The hybridized synchronous reluctance machine improved the major constraints of conventional reluctance machine - low power output and poor power factor due to low ratio of direct to quadrature axis reactance $\left(\mathrm{X}_{\mathrm{d}} / \mathrm{X}_{\mathrm{q}}\right)$. To achieve this two elemental synchronous machines was conceived. Both were internally wound with identical winding in the stator. The rotor of one of the synchronous reluctance machine component is round while the other has a salient pole. Both machine halves were mechanically coupled together. One set of the winding of both machines were connected in series and fed from the main while the other set was also connected in series (but transposed between the two section of the of the machine) and then connected to a balanced three phased variable capacitance load. It was the capacitance loading of the auxiliary winding makes the overall $\mathrm{X}_{\mathrm{d}} / \mathrm{X}_{\mathrm{q}}$ ratio of the hybrid machine to be variable that can theoretically attain values between zero and infinity. This translates to ultra-high output and unity power factor.

Keyword: $X_{d} / X_{q}$ ratio, dual-winding machines, power factor, two-axis theory.

\section{INTRODUCTION}

A synchronous machine is an ac rotating machine whose speed under steady state condition is proportional to the frequency of the current in its armature. The magnetic field created by the armature currents rotates at the same speed as that created by the field current on the rotor, which is rotating at the synchronous speed, and a steady torque results. Almost all the electric power used throughout the world is generated by synchronous machine driven either by hydro, steam turbine or combustion engine. Just as the induction machine is the workhorse when it comes to converting energy from electrical to mechanical, the synchronous machine is the principal means of converting energy from mechanical to electrical. Thus, the fundamental difference between a synchronous machine and an induction machine is that the rotor currents of the induction machine are induced while those of the synchronous machine are not. The rotor of synchronous machine is equipped with a field winding and one or two damper windings. The rotor windings have different characteristics [1].

A good number of researches done on synchronous reluctance machine in the past three decades have suggested the machine to be an attractive alternative to other AC machines (permanent magnet, Induction and Switched reluctance machines) in high performance, variable speed applications. This is as a result of the ability of the machine to withstand harsh environment, its low inertia, ease of construction, high power to weight ratio and good acceleration performance [3-10]. Anih L U [2] coupled two machines- the salient pole machine and a round rotor machine. Each of the machines has two separate windings; the main and auxiliary windings, with the main windings connected in series while the auxiliary windings are connected in anti-series and feed a capacitor. He used the electric circuit theory method 
to show that the ratio of $\mathrm{L}_{\mathrm{d}} / \mathrm{L}_{\mathrm{q}}$ can be increased to infinity by varying the capacitance values. Subsequently the study of reluctance machines has been extended to coupled machine in which the combination of round and salient pole machine is one of them [10]. Different rotor configurations have gone through different design analysis and techniques to obtain a better performance. Some of the successes on the rotor configurations are well reported in [5], [6], [11]-[14]. The geometric approach via rotor designs has improved the performance characteristics of reluctance machines. Since 1963, Lawrenson and Agu $[15,16,17]$ extensively developed the segmental rotor design. Lawrenson improved his segmental rotors by introducing q-axis channels [18] and used them for both single-speed [18] and multi-speed [19] applications. Due to the larger saliency ratio, he obtained performance better than equivalent conventional machine designs

\section{Description of the Hybrid Machine}

The machine comprises two machines of a salient pole and a round rotor that are integrally wound and mechanically coupled together. Each machine unit has two sets of three-phase windings that are identifiable as the main and auxiliary windings respectively. The main windings of both machines are connected in series; the auxiliary windings are also connected in series but transposed in passing from one machine to the other and short-circuited. By tuning the load capacitance of the auxiliary winding, it begins to vary the operational q-axis reactance $\left(\mathrm{X}_{\mathrm{q}}\right)$ of the machine from zero to infinity, while the $\mathrm{d}$-axis reactance $\left(\mathrm{X}_{\mathrm{d}}\right)$ remains constant. Thus a variable $\mathrm{X}_{\mathrm{d}} / \mathrm{X}_{\mathrm{q}}$ ratio is achieved which varies from zero to infinity and hence the output power which is directly proportional to it. Fig. 1 below shows the connection diagram of the hybrid machine.

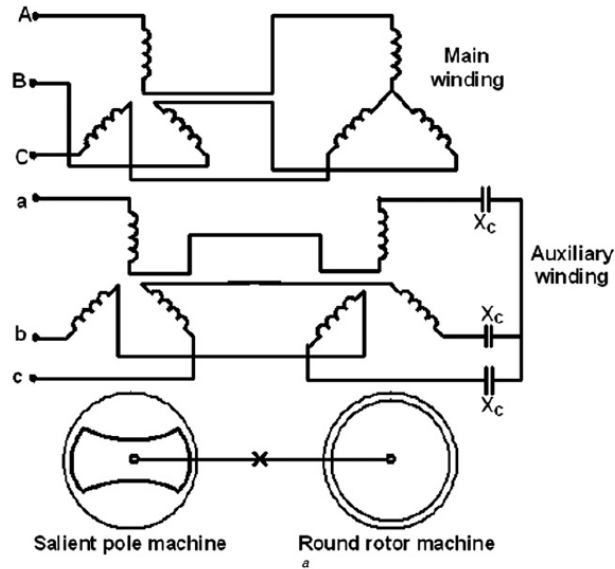

Fig.1 Connection Diagram for Main Winding of the Hybrid Machine

\section{Fundamental Concept of the hybrid synchronous reluctance machine}

The synchronous reactance of the round rotor is $X_{S}$ and the direct axis reactance of the salient pole is $X_{d}$. When the salient pole operates on the $\mathrm{d}$-axis and the synchronous reactance is made equal $X_{d}$. The

overall reactance is $X_{D}=x_{d}+x_{d}=2 X_{d}$

When the salient pole operates on the q-axis the overall reactance $X_{Q}=x_{d}+x_{q}$

However the operation of a synchronous machine is dependent on $X_{D} / X_{Q}$ ratio. The preliminary analytic study shows that if the auxiliary winding transposed between the two machines feeds a balanced capacitance load, the overall $X_{Q}$ is reduced while the $X_{D}$ remains unaffected. It therefore follows that for a typical value of $X_{C}$ that $X_{Q}$ can be even zero resulting in an ultra-high output power.

\section{Hybrid Machine Model Development}

Since synchronous machine generally operate as generators, it is convenient to assume that the direction of the positive current is out of the terminal of the stator windings. The model presented here is for a machine that has no rotor conductors, as the primary interest here is the steady state performance of the machine at differing capacitance values. In the analysis that follows, upper case subscripts represent main winding terms while the lower case subscripts are for the auxiliary winding terms. The model developed relies on the usual assumptions of modelling synchronous machines as contained in classical texts [14] and [17] and on the semi intuitive per-phase circuit shown inFigure 2.

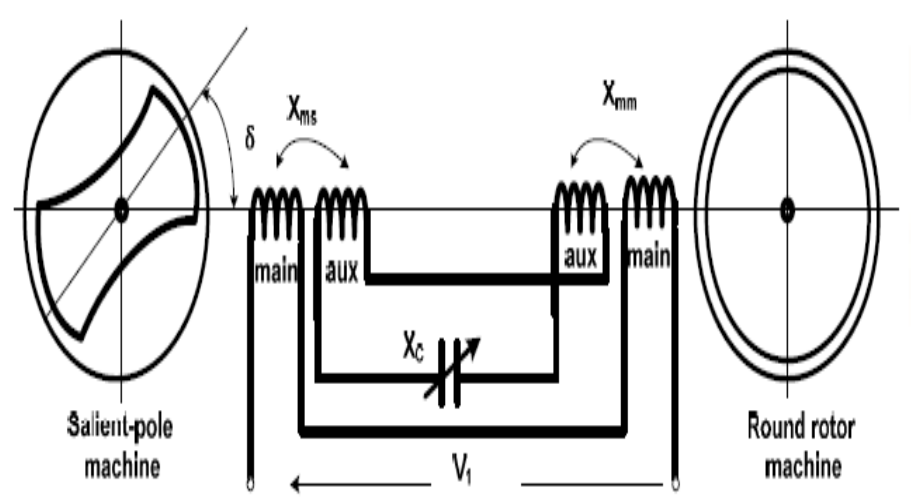

Figure 2: Per-phase connection circuit of the hybrid machine 
Six voltage equations for the hybrid machine in stator reference frame can be written as;

where $\mathrm{V}_{\mathrm{E}}$ represents the main and auxiliary winding voltages and is given in matrix form by;

$$
V_{E}=\left[\begin{array}{ll}
V_{A B C} & V_{a b c}
\end{array}\right]=\left[\begin{array}{llllll}
V_{A} & V_{B} & V_{C} & V_{a} & V_{b} & V_{c}
\end{array}\right]^{T}
$$

The current matrix is given by;

$$
I_{E}=\left[\begin{array}{lll}
I_{A B C} & I_{a b c}
\end{array}\right]=\left[\begin{array}{llllll}
I_{A} & I_{B} & I_{C} & I_{a} & I_{b} & I_{C}
\end{array}\right]^{T}
$$

The resistance matrix is given by;

$$
R_{E}=\operatorname{diag}\left\lfloor R_{A} R_{B} R_{C} R_{a} R_{b} R_{C}\right\rfloor
$$

In the above equations and everywhere in this report, upper case subscript will represent main winding quantities and lower case subscript will represent auxiliary winding quantities. Thus the flux linkage $\left(\lambda_{E}\right)$ equation in phase variable becomes;

$$
\lambda_{E}=\left[\begin{array}{ll}
L_{11} & L_{12} \\
L_{21} & L_{22}
\end{array}\right]\left[\begin{array}{c}
I_{A B C} \\
I_{a b c}
\end{array}\right]=\left[\begin{array}{cc}
L_{S S}+L_{R R} & L_{M S}+L_{M R}-2 L_{L} \\
L_{M S}+L_{M R}-2 L_{L} & L_{S S}+L_{R R}
\end{array}\right]\left[\begin{array}{c}
I_{A B C} \\
I_{a b c}
\end{array}\right] .
$$

This implies that;

where;

$$
\lambda_{E}=\left[\begin{array}{c}
\lambda_{A B C S} \\
\lambda_{a b c S}
\end{array}\right]\left[\begin{array}{c}
I_{A B C S} \\
I_{a b c S}
\end{array}\right]=\left[\begin{array}{cc}
L S R M & \text { MUTA } \\
M U T M & L S R A
\end{array}\right]\left[\begin{array}{c}
I_{A B C S} \\
I_{\text {abcS }}
\end{array}\right]
$$

LSRM is the inductance matrix of the main windings connected in series $=\mathrm{L}_{11}$. MUTA is the mutual inductance matrix between the main and auxiliary windings as seen by the auxiliary winding current $=\mathrm{L}_{12}$. MUTM is the mutual inductance matrix between the main winding and auxiliary winding as seen by the main winding current $=\mathrm{L}_{21}$. LSRA is the inductance matrix of the auxiliary winding $=\mathrm{L}_{22}$. In equation (4), $\lambda_{E}$ is a matrices representing;

$L_{S S}$ which is a $3 \times 3$ inductance matrix of the stator three phase winding in the salient pole half of the machine and, $L_{R R} 3 \times 3$ inductance matrix of the round rotor part of the machine.

Each of the $L_{R R}$ and $L_{S S}$ has their respective leakage parts in the appropriate places in (9) and (13). Since we assumed that the main and auxiliary windings are identical and both are mutually coupled and occupy the same slot positions, we equate the mutual inductance between the set of main and auxiliary windings. $L_{L}$ is the $3 \times 3$ leakage inductance matrix of any of the winding of either the round rotor and salient pole halves of the hybrid machine which are also equal. The inductance of the two main windings connected in series represented by LSRM is given as;

\section{$L S R M=L_{R R}($ Round RotorMachine $)+L_{S S}($ Salient poleMachine $)$$$
=L_{R R}+L_{S S}
$$

The total inductance of auxiliary winding represented by LSRA is given as;

$$
\text { LSRA = LSRM }
$$

But

$$
L S R M=\left[\begin{array}{ccc}
L_{l s}+\frac{2}{3} L_{m d} & -\frac{1}{3} L_{m d} & -\frac{1}{3} L_{m d} \\
-\frac{1}{3} L_{m d} & L_{l s}+\frac{2}{3} L_{m d} & -\frac{1}{3} L_{m d} \\
-\frac{1}{3} L_{m d} & -\frac{1}{3} L_{m d} & L_{l s}+\frac{2}{3} L_{m d}
\end{array}\right]+\left[\begin{array}{ccc}
L l_{s}+L_{o}-L_{m s} \cos \left(2 \theta_{r}\right) & -\frac{1}{2} L_{o}-L_{m s} \cos 2\left(\theta_{r}-\frac{\pi}{3}\right) & -\frac{1}{2} L_{o}-L_{m s} \cos 2\left(\theta_{r}+\frac{\pi}{3}\right) \\
-\frac{1}{2} L_{o}-L_{m s} \cos 2\left(\theta_{r}-\frac{\pi}{3}\right) & L l_{s}+L_{o}-L_{m s} \cos 2\left(\theta_{r}-\frac{2 \pi}{3}\right) & -\frac{1}{2} L_{o}-L_{m s} \cos 2\left(\theta_{r}+\pi\right) \\
-\frac{1}{2} L_{o}-L_{m s} \cos 2\left(\theta_{r}+\frac{\pi}{3}\right) & -\frac{1}{2} L_{o}-L_{m s} \cos 2\left(\theta_{r}+\pi\right) & L l_{s}+L_{o}-L_{m s} \cos 2\left(\theta_{r}+\frac{2 \pi}{3}\right)
\end{array}\right]
$$

The inductance matrix for any of the two stator windings of the salient pole machine is well known from literature [20] and is given as: 
International Journal of Trend in Scientific Research and Development (IJTSRD) ISSN: 2456-6470

$$
\begin{gathered}
L_{S S}=\left[\begin{array}{ccc}
L_{l s}+L_{o}-L_{m s} \cos 2 \theta_{r} & -\frac{1}{2} L_{o}-L_{m s} \cos 2\left(\theta_{r}-\frac{\pi}{3}\right) & -\frac{1}{2} L_{o}-L_{m s} \cos 2\left(\theta_{r}+\frac{\pi}{3}\right) \\
-\frac{1}{2} L_{o}-L_{m s} \cos 2\left(\theta_{r}-\frac{\pi}{3}\right) & L_{l s}+L_{o}-L_{m s} \cos 2\left(\theta_{r}-\frac{2 \pi}{3}\right) & -\frac{1}{2} L_{o}-L_{m s} \cos 2\left(\theta_{r}+\pi\right) \\
-\frac{1}{2} L_{o}-L_{m s} \cos 2\left(\theta_{r}+\frac{\pi}{3}\right) & -\frac{1}{2} L_{o}-L_{m s} \cos 2\left(\theta_{r}+\pi\right) & L_{l s}+L_{o}-L_{m s} \cos 2\left(\theta_{r}+\frac{2 \pi}{3}\right)
\end{array}\right] \\
\text { Where } L_{o}=\frac{L_{m d}+L_{m q}}{3} \\
\text { and, } \quad L_{m}=\frac{L_{m d}-L_{m q}}{3}
\end{gathered}
$$

The leakage inductance matrix is;

$$
L_{L}=\operatorname{diag}\left[\begin{array}{lll}
L_{L S} & L_{L S} & L_{L S}
\end{array}\right]
$$

But, For the round rotor machine half of the machine $L_{m d}=L_{m q}$, and $L_{m s}=L_{m d}$. This implies that $L_{o}=\frac{2}{3} L_{m d}$ and $L_{m}=0$, so its stator winding inductance matrix can be obtained by substituting the values of $L_{o}$ and $L_{m}$ into equation (12). Thus;

$$
L_{R R}=\left[\begin{array}{ccc}
L_{l s}+L_{o}-L_{m} & -\frac{1}{2} L_{o}-L_{m} & -\frac{1}{2} L_{o}-L_{m} \\
-\frac{1}{2} L_{o}-L_{m} & L_{l s}+L_{o}-L_{m} & -\frac{1}{2} L_{o}-L_{m} \\
-\frac{1}{2} L_{o}-L_{m} & -\frac{1}{2} L_{o}-L_{m} & L_{l s}+L_{o}-L_{m}
\end{array}\right]
$$

Therefore stator winding inductance matrix $L_{R R}$ becomes:

$$
\boldsymbol{L}_{R R}=\left[\begin{array}{ccc|c}
\boldsymbol{L}_{l s}+\frac{2}{3} \boldsymbol{L}_{m d} & -\frac{1}{3} \boldsymbol{L}_{m d} & -\frac{1}{3} \boldsymbol{L}_{m d} \\
-\frac{1}{3} \boldsymbol{L}_{m d} & \boldsymbol{L}_{L s}+\frac{2}{3} \boldsymbol{L}_{m d} & -\frac{1}{3} \boldsymbol{L}_{m d} \\
-\frac{1}{3} \boldsymbol{L}_{m d} & -\frac{1}{3} \boldsymbol{L}_{m d} & \boldsymbol{L}_{l s}+\frac{2}{3} \boldsymbol{L}_{m d}
\end{array}\right]
$$

Substituting (8) and (12) into (8), and making The LSRM inductance matrix becomes;

$$
\begin{gathered}
\left.L S R M=\text { LSRA, }=\begin{array}{ccc}
A-B \cos \left(2 \theta_{r}\right) & C-B \cos \left(2 \theta_{r}-\frac{2 \pi}{3}\right) & C-B \cos 2\left(\theta_{r}+\frac{2 \pi}{3}\right) \\
C-B \cos \left(2 \theta_{r}-\frac{2 \pi}{3}\right) & A-B \cos \left(2 \theta_{r}-\frac{4 \pi}{3}\right) & C-B \cos \left(2 \theta_{r}\right) \\
C-B \cos \left(2 \theta_{r}+\frac{2 \pi}{3}\right) & C-B \cos \left(2 \theta_{r}\right) & A-B \cos \left(2 \theta_{r}+\frac{4 \pi}{3}\right)
\end{array}\right] \\
M U T M=\text { MUTA }=\left[\begin{array}{ccc}
D-B \cos 2 \theta_{r} & F-B \cos \left(2 \theta_{r}-\frac{2 \pi}{3}\right) & F-B \cos \left(2 \theta_{r}+\frac{2 \pi}{3}\right) \\
F-B \cos \left(2 \theta_{r}-\frac{2 \pi}{3}\right) & D-B \cos \left(2 \theta_{r}-\frac{4 \pi}{3}\right) & F-B \cos 2 \theta_{r} \\
F-B \cos \left(2 \theta_{r}+\frac{2 \pi}{3}\right) & F-B \cos 2 \theta_{r} & D-B \cos \left(2 \theta_{r}+\frac{4 \pi}{3}\right)
\end{array}\right] \\
A=2 L_{l s}+L_{m d}+\frac{1}{3} L_{m q}, \quad B=\frac{1}{3}\left(L_{m d}-L_{m q}\right), \quad C=-\frac{1}{2} L_{m d}-\frac{1}{6} L_{m q}, \quad D=\frac{1}{3}\left(L_{m d}+L_{m q}\right), \quad E=-\frac{1}{6}\left(L_{m d}-L_{m q}\right), \quad F=\frac{1}{6}\left(L_{m d}-L_{m q}\right)
\end{gathered}
$$

The entire stator winding inductance matrix given in equation (16).

$$
\left[\begin{array}{c}
\lambda_{A B C S} \\
\lambda_{a b c s}
\end{array}\right]=\left[\begin{array}{cc}
L S R M & M U T A \\
M U T M & L S R A
\end{array}\right]\left[\begin{array}{c}
-I_{A B C S} \\
-I_{a b c s}
\end{array}\right]
$$

If we denote equation (16)by $\lambda_{F}$, then;

Substituting the expressions of $L S R M$, MUTA, MUTM, LSRA into the matrix of $\lambda_{F}$ gives; 
International Journal of Trend in Scientific Research and Development (IJTSRD) ISSN: 2456-6470

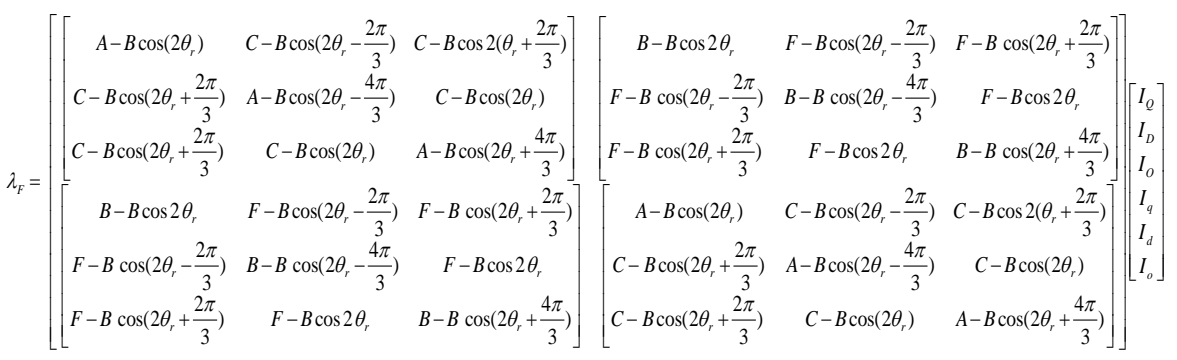

\subsection{Transformation to dqo}

It is seen that every element of the sixth order inductance matrix is dependent on rotor position $\theta_{r}$. Therefore, a

transformation to rotor reference frame is suitable to eliminate this dependence. We adopt Park's transformation equation, $\quad F_{d q o}=\left[T_{d q o}\left(\theta_{r}\right)\right]\left[F_{a b c}\right] \quad$ where the $d q o$ transformation matrix is defined as;

$$
\left[T_{d q o}\left(\theta_{r)}\right]=\frac{2}{3}\left[\begin{array}{ccc}
\cos \theta_{r} & \cos \left(\theta_{r}-\frac{2 \pi}{3}\right) & \cos \left(\theta_{r}+\frac{2 \pi}{3}\right) \\
\sin \theta_{r} & \sin \left(\theta_{r}-\frac{2 \pi}{3}\right) & \sin \left(\theta_{r}+\frac{2 \pi}{3}\right) \\
\frac{1}{2} & \frac{1}{2} & \frac{1}{2}
\end{array}\right]\right.
$$

The transformation will be performed on the entire inductance matrix $\lambda_{F}$ since all of them are on the stator, so the augmented matrix will become $\lambda_{F}$

$$
\lambda_{F}=\left[\begin{array}{cc}
{\left[T _ { d q o } ( \theta _ { r ) } ] ^ { * } \operatorname { L S R M } * \left[T_{d q o}\left(\theta_{r)}\right]^{-1}\right.\right.} & {\left[T _ { d q o } ( \theta _ { r ) } ] ^ { * } \operatorname { M U T A } * \left[T_{d q o}\left(\theta_{r)}\right]^{-1}\right.\right.} \\
{\left[T _ { d q o } ( \theta _ { r ) } ] ^ { * } \operatorname { M U T M } * \left[T_{d q o}\left(\theta_{r)}\right]^{-1}\right.\right.} & {\left[T _ { d q o } ( \theta _ { r ) } ] ^ { * } L S R A * \left[T_{d q o}\left(\theta_{r)}\right]^{-1}\right.\right.}
\end{array}\right]
$$

where; the transformation $\left[\begin{array}{cc}L_{Q D S} & L_{Q D A} \\ L_{Q D M} & L_{Q D R}\end{array}\right]$ te yields,

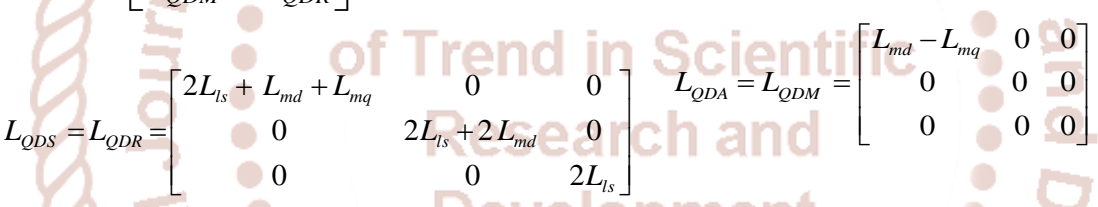

The entire inductance matrix for stator reference frame yields,

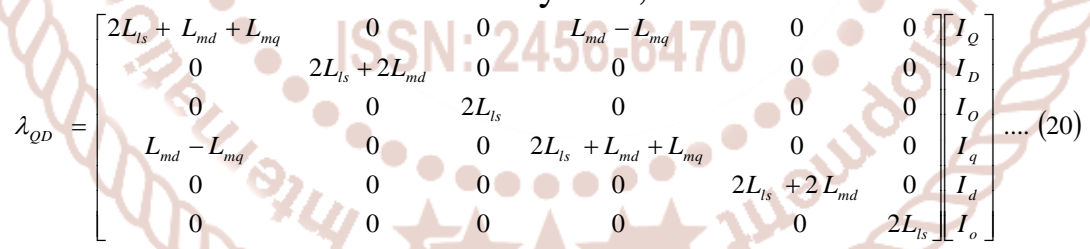

It is easy to observe that the d-axis and q-axis flux linkages for the winding sets are:

$$
\begin{gathered}
\lambda_{D d}=\left[\begin{array}{l}
\lambda_{D} \\
\lambda_{d}
\end{array}\right]=\left[\begin{array}{cc}
2\left(L_{l s}+L_{m d}\right) & 0 \\
0 & 2\left(L_{l s}+L_{m d}\right)
\end{array}\right]\left[\begin{array}{c}
I_{D} \\
I_{d}
\end{array}\right] \ldots \ldots . . . \\
\lambda_{Q q}=\left[\begin{array}{l}
\lambda_{Q} \\
\lambda_{q}
\end{array}\right]=\left[\begin{array}{cc}
\left.2 L_{l s}+L_{m d}+L_{m q}\right) & -\left(L_{m d}-L_{m q}\right) \\
-\left(L_{m d}-L_{m q}\right) & \left(2 L_{l s}+L_{m d}+L_{m q}\right)
\end{array}\right]\left[\begin{array}{c}
I_{Q} \\
I_{q}
\end{array}\right] \\
\lambda_{O o}=\left[\begin{array}{c}
\lambda_{O} \\
\lambda_{0}
\end{array}\right]=\left[\begin{array}{cc}
2 L_{l s} & 0 \\
0 & 2 L_{l s}
\end{array}\right]\left[\begin{array}{c}
I_{O} \\
I_{o}
\end{array}\right] \ldots \ldots \ldots \ldots . . . . . . .
\end{gathered}
$$

Equation (21) shows that the overall d-axis inductances of the two windings sets are the same and completely uncoupled while the overall inductance matrix of (22) shows the existence of a coupling term. This explains why the d-axis reactance of the hybrid machine remains constant when the capacitive loading of the auxiliary winding is varied and the q-axis reactance also varies.

\subsection{Capacitor Voltage Equation}


Capacitors have long been proven as power factor correcting devices. To use capacitors to assist an a.c motor, there ought to be two sets of windings because if the capacitors are connected in series to a single-winding machine, the impedance is drastically reduced and intolerably high current will be drawn. And if connected in parallel the power factor of the supply source is improved with negligible improvement in motor performance. A salient pole and round-rotor machine, each possessing two sets of windings were coupled together, the main windings connected in series and powered from the mains while the auxiliary windings were specifically connected to a balanced capacitor.

For the 3 - phase capacitive circuit connected to the auxiliary windings;

$$
i_{a b c s}=\frac{d}{d t} q_{a b c s}
$$

Applying Park's transformation equations yields $p v_{q c}=\frac{i_{q c}-\omega_{r} c v_{d c}}{c}$ and $p v_{d c}=\frac{i_{d c}+\omega_{r} c v_{q c}}{c}$

At steady state the values of the derivatives are set to zero, hence

$$
V_{d}=X_{c} i_{q c} \text { and }-X_{c} i_{d c}
$$

\subsection{Hybrid Machine Voltage Equation in dqo Variables}

The hybrid machine voltage equations in dqo variable are obtained for the main and auxiliary windings. Also the capacitive voltage equation is incorporated into the voltage equation for the auxiliary winding since the capacitor is connected to the auxiliary winding. In general, the voltage equation can be expressed in abcs and dqos as;

$$
\begin{aligned}
& V_{D S}=-2 R_{S} I_{D S}-\omega \lambda_{Q S}+P \lambda_{D S} \text { ternat } \\
& V_{Q S}=-2 R_{S} I_{Q S}+\omega \lambda_{D S}+P \lambda_{Q S} \text { Tren } \\
& V_{O S}=-2 R_{S} I_{o s}+P \lambda_{o S} \\
& V_{d s}=-2 r_{S} I_{d s}-\omega \lambda_{q s}+P \lambda_{d s}+V_{c d} \\
& V_{q s}=-2 r_{S} I_{q s}+\omega \lambda_{d s}+P \lambda_{q s}+V_{c q} \\
& V_{o s}=-2 r_{S} I_{o s}+P \lambda_{o s}
\end{aligned}
$$

The dynamic equivalent circuit of the hybrid machine can be drawn based on equations (25) to (30) and shown in fig. 3

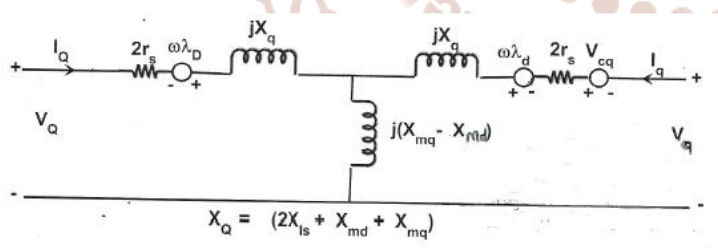

(a)

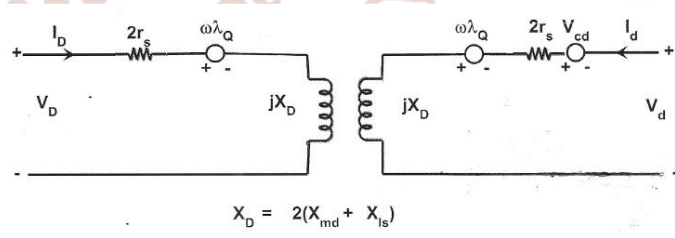

(b)

Figure 3 Dynamic equivalent circuit of the hybrid machine (a) q-axis (b) d-axis

\section{Steady State Analysis Of The Hybrid Machine}

In this section the steady state operation is examined to help us better understand the operational behavior of the machine.

For the purpose of examining the steady-state performance of this machine, the parameters of a 4-pole, 2hp, $220 \mathrm{~V}, 50 \mathrm{~Hz}$, synchronous reluctance machine [16] was used. The unsaturated reactances are $\mathrm{X}_{\mathrm{md}}=124.21 \Omega$, $\mathrm{X}_{\mathrm{mq}}=78.72 \Omega$ and $\mathrm{X}_{\mathrm{ls}}=12.0 \Omega$. Since the stator winding of the machine is halved, the reactances will be divided by a factor of 4 which will now give: $X_{m d}=31.05 \Omega ; X_{m q}=19.67 \Omega$ and $X_{1 s}=3.0 \Omega$.

At synchronous speed the steady state mode, the following relationships exist between main winding and the auxiliary winding rotor reference frame, steady state variable and the synchronous rotating phasor. 


$$
\begin{aligned}
F_{A S} & =\left(F_{Q S}-J F_{D S}\right) e^{j \partial} \\
F_{a S} & =\left(F_{q s}-J F_{d s}\right) e^{j \partial}
\end{aligned}
$$

Where, $\quad$ F can be voltage, current or flux linkage

$\partial$ is the load angle. $V_{Q S}=\mathrm{V} \cos \partial \quad V_{D S}=\mathrm{V} \sin \partial$

Where, $\mathrm{V}$ is the root mean square value of the supply voltage and $\partial$ is the load angle.

$$
\begin{gathered}
V_{A S} e^{-j \partial}=2 R_{S} I_{A}-2 X_{d} I^{r}{ }_{A}-j\left(X_{d}-X_{q}\right) I^{r} Q S-j\left(X_{m d}-X_{m q}\right) I_{q s}^{r} \\
V_{a s} e^{-j \partial}=2 R_{S} I_{a}+2 X_{d} I^{r}{ }_{a}+X_{C} I_{a}-j\left(X_{d}-X_{q}\right) I^{r}{ }_{q s}-j\left(X_{m d}-X_{m q}\right) I^{r} Q S
\end{gathered}
$$

It is now possible to assess the machine parameter variation in the steady-state using the equivalent circuit shown if figure 3.2

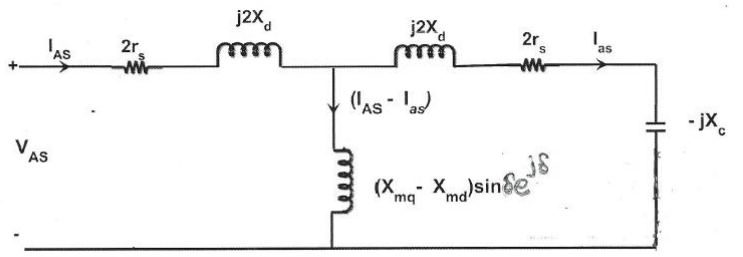

Figure 4 Per-phase steady state equivalent circuit of the hybrid machine

\subsection{Input impedance}

The machine input impedance can be obtained by finding the ratio of the input voltage $\mathrm{V}_{\mathrm{AS}}$ to the main winding current, $\mathrm{I}_{\mathrm{AS}}$ employing (35) or by using simple circuit theory approach of looking into the input terminals of Figure 4. Both approaches will naturally give the same results, however for brevity we use the later and show that the input impedance is given as:

$$
Z=2\left(r_{s}+j X_{d}\right)+\frac{\left(2 r_{s}+j\left(2 X_{d}-X_{c}\right)\right) X\left(X_{m q}+X_{m d}\right) \sin \partial e^{j o}}{\left(2 r_{s}+\left(X_{m q}-X_{m d}\right)\right) \sin \partial e^{j \delta}+j\left(2 X_{d}-X_{c}\right)}
$$

\subsection{Axes reactances of the machine}

In general, the impedance expression can be resolved to real $(\mathrm{Re})$ and imaginary $(\mathrm{Xe})$ terms. Aplot of real versus the imaginary part of (35) for various values of $X_{c}$ with $\delta$ ranging from 0 to $\pi$ generates a family of circles as shown in Figure 6. Each of these circles (impedance loci) has aconstant d-axis reactance equal to $2 X_{D}+\left(X_{l s}+X_{m d}\right)$ but the quadrature axis reactance $X_{Q}$ varies.

\subsubsection{Direct axis reactance}

Using (28) in the limit that $\delta \rightarrow \mathbf{O}$ and for negligible stator winding resistance, the overall d-axis reactance is $\mathrm{X}_{\mathrm{D}}$ given by (36) which is clearly independent of the capacitive reactance:

$$
X_{D}+j 2\left(X_{l s}+X_{m d}\right)
$$

\subsubsection{Quadrature axis reactance}

In the limit that $\delta \rightarrow \frac{\pi}{2}$ and for negligible stator winding resistance, the overall q-axis reactance is $\mathrm{X}_{\mathrm{Q}}$ given by:

$$
X_{Q}=j \frac{4 X_{m d}\left(X_{l s}+X_{m d}+X_{m q}\right)+4 X_{l s}-\left(2 X_{l s}+X_{m d}+X_{m q}\right) X_{c}}{2 X_{l s}+X_{m d}+X_{m q}-X_{c}}
$$


Evidently, it can be seen that only the effective quadrature axis impedance is influenced by the capacitance connected to the auxiliary winding.

\section{$5.3 \mathrm{X}_{\mathrm{d}} / \mathbf{X}_{\mathrm{q}}$ ratio}

The effective reactance ratio, $\mathrm{X}_{\mathrm{D}} / \mathrm{X}_{\mathrm{Q}}$ of the hybrid machine can be closely examined by taking the ratio of (36) to (37). It is easier to visualize this reactance ratio graphically as shown in Figure 6 where for varying $X_{C}$ plots of $\mathrm{X}_{\mathrm{D}}, \mathrm{X}_{\mathrm{Q}}$ and then $\mathrm{X}_{\mathrm{D}} / \mathrm{X}_{\mathrm{Q}}$ are shown. In the plot, the values of capacitor (in $\mu \mathrm{F}$ ) are given instead of $\mathrm{XC}$ in order to justify that realistic values exist for evena value of zero quadrature axis reactance. From (37) it can be shown that analytically, zeroquadrature axis reactance can be obtained when:

$$
X_{c}=\frac{4\left(X_{m d} X_{m q}+X_{l s} X_{m q}+X_{l s} X_{m d}\right)}{2 X_{l s}+X_{m d}+X_{m q}}
$$

For the machine under study this translates to a capacitance of about $67.4 \mu \mathrm{F}$.

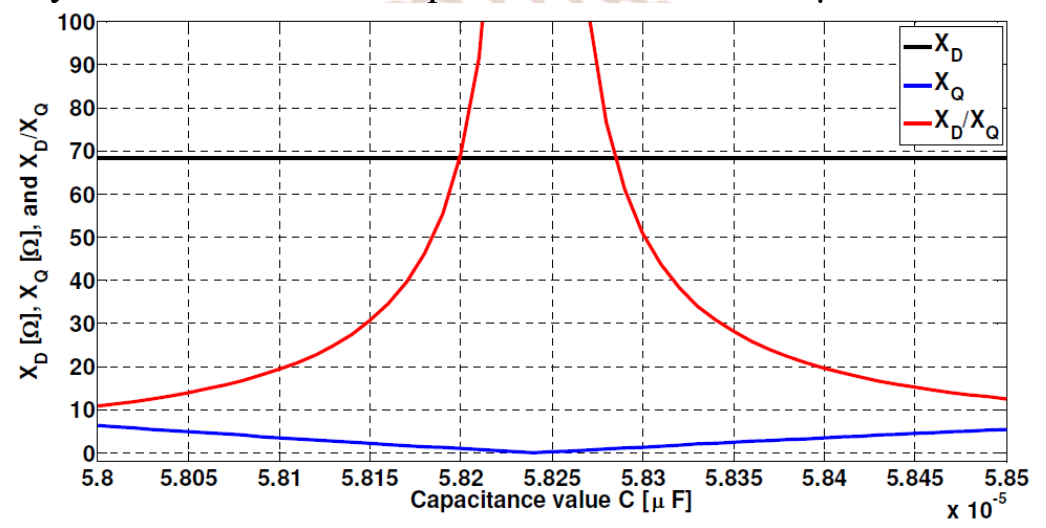

Figure 15: Variation of reactances and the reactance ratio with capacitance

\subsection{Circle diagrams}

Examination of (35) shows that the loci of $\mathrm{Z}$ for different values of capacitance loading of the auxiliary winding $\mathrm{X}_{\mathrm{C}}$ as $\delta$ varies from 0 to $\pi$ are family of circles with center: $\left[0,\left(\mathrm{X}_{\mathrm{D}}+\mathrm{X}_{\mathrm{Q}}\right)\right]$ and radius . $\left(\mathrm{X}_{\mathrm{D}}-\mathrm{X}_{\mathrm{Q}}\right)$ where $\mathrm{X}_{\mathrm{Q}}$ is a variable parameter, which depends on $\mathrm{X}_{\mathrm{C}}$.

All the circles are tangential to the line $X_{D}=2 X_{d}$. The quadrature axis reactance $\mathrm{X}_{\mathrm{Q}}$ thus changes as $\mathrm{X}_{\mathrm{C}}$ changes as shown in Figure $6 \mathrm{a}$ while the $\mathrm{d}$-axis reactance remains constant. For each impedance locus, there is a corresponding current locus. Each of the current loci is tangential to $\mathrm{I}_{\mathrm{AS}}=\mathrm{V}_{\mathrm{AS}} /\left(2 \mathrm{X}_{\mathrm{d}}\right)$ point as shown in Figure 6b. The centers of such circles will lie on the horizontal axis from $+\infty$ to $-\infty$. The q-axis reactance can even be negative and may be greater than $X_{D}$ in magnitude. The horizontal line $\operatorname{Real}(Z)=0$ which corresponds to $\operatorname{Real}\left(\mathrm{I}_{\mathrm{AS}}\right)=0$ as shown in Figure 6 marks the transition of the machine from generating to motoring operations. At these points, the machine is neither motoring nor generating and the input power VIcos $\varphi$ supplies the winding losses only.
It is observed from Figure 6 that without the auxiliary winding $\left(X_{C}=\infty\right)$, the value of $X_{D}=60 \Omega$ while the quadrature axis $\mathrm{X}_{\mathrm{Q}}=50 \Omega$, giving a very low $\mathrm{X}_{\mathrm{D}} / \mathrm{X}_{\mathrm{Q}}$ ratio. The introduction of a variable capacitance load into the auxiliary winding makes the quadrature axis reactance $\mathrm{X}^{\mathrm{Q}}$ variable and can be made to vary from zero to infinity. Some of the loci of the hybrid machine are of special interest. For $X_{C}=1.6 X_{d}$, the quadrature axis reactance $\mathrm{X}_{\mathrm{Q}}$ is completely

neutralized, (i.e. $X_{Q}=0$ ) by the capacitive reactance leading to infinitely high output power and unity power factor. Further increase in $\mathrm{X}_{\mathrm{C}}$ between $1.6 \mathrm{X}_{\mathrm{d}}$ and $1.67 \mathrm{X}_{\mathrm{d}}, \mathrm{X}_{\mathrm{Q}}$ becomes negative and the power factor becomes leading. For the capacitive reactance $\mathrm{X}_{\mathrm{C}}=1.64 \mathrm{X}_{\mathrm{d}}$, the center of the impedance locus coincides with the origin, i.e. $\left|-X_{Q}\right|=\left|X_{D}\right|$, the machine draws or supplies the same current irrespective of load. When the current loci embraces the third quadrant, the machine is able as a generator to supply lagging power factor loads and as a motor to supply leading power factor loads. For $\mathrm{X}_{\mathrm{C}}=1.67 \mathrm{X}_{\mathrm{d}}, \mathrm{X}_{\mathrm{Q}}$ is infinite and the corresponding current locus is $\mathrm{I}_{\mathrm{Q}}=0$. The significance of this is that $\mathrm{X}_{\mathrm{Q}}$ is now greater than 
$\mathrm{X}_{\mathrm{D}}$ and the operating axis of the machine shifts by $\pi$ radians and the Q-axis now becomes the no-load axis.

Between $\mathrm{X}_{\mathrm{C}}=1.67 \mathrm{X}_{\mathrm{d}}$ and $2 \mathrm{X}_{\mathrm{d}}$, the impedance loci flip over to the right hand of $\mathrm{X}_{\mathrm{Q}}=\infty$ axis, inductive in nature and shrinking. The shrinking of the flipped loci is because the capacitive reactance is becoming large and thus increasing the impedance of the auxiliary winding towards the open-circuit case, which is inductive in nature and in consequence, the current in the auxiliary winding decreases. Although resistance was neglected in the plots its inclusion would have shifted the impedance and current loci vertically upwards above the horizontal axis by an amount equal to the value of the resistance.

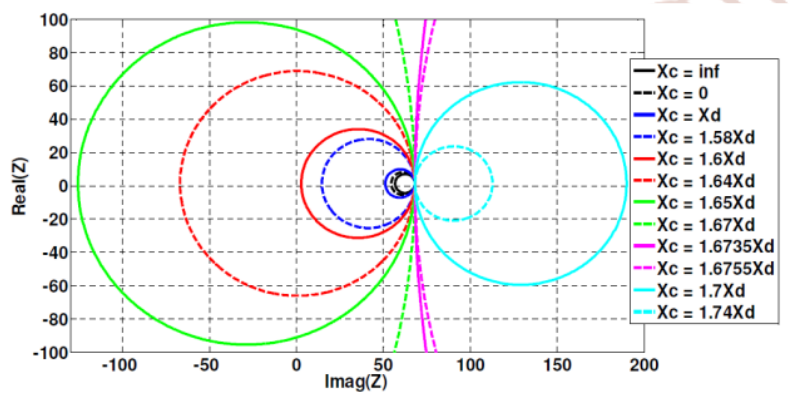

(a)

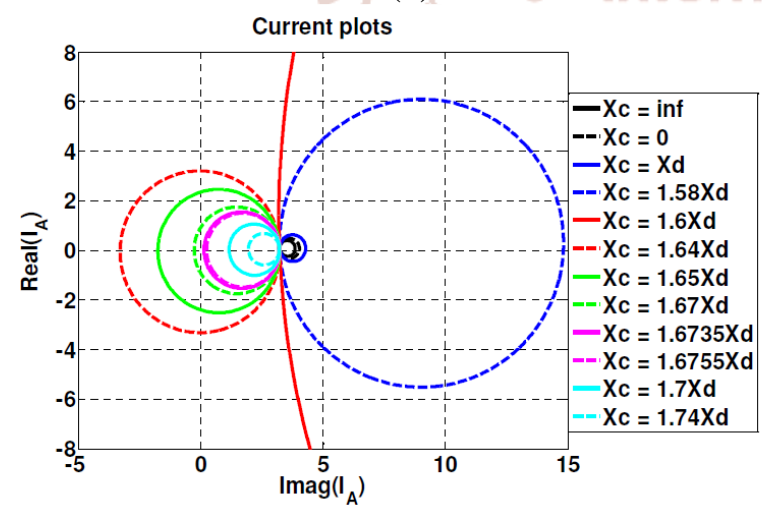

(b)

Figure 6: (a) Impedance loci, (b) Current loci.

\subsection{Power factor}

The power factor of the hybrid machine is easily obtained from ac circuit theory as:

$$
\cos \varphi=\frac{\mathrm{Re}}{\sqrt{\mathrm{Re}^{2}}+X e^{2}}
$$

For the same set of values of $X_{C}$ as used before, a plot of power factor for a range of $\delta$ ranging from 0 to $45^{\circ}$ is as shown in Figure 7. Here it is evident that the power factor appreciates as the value of capacitive reactance approaches the value need for zero quadrature axis reactance.

\section{Comparison of the Conventional Reluctance Machine with the Synchronous Hybrid Machine.}

The synchronous hybrid machine differs greatly from conventional reliance machine in various way as shown below.

\subsection{Constructional features:}

The synchronous hybrid machine consists of two machine elements that are mechanically coupled together and their stators are integrally wound while the conventional reluctance machine consists of one machine element. Each stator of the synchronous hybrid machine consists of two windings called main and auxiliary winding. In order to accommodate the two windings the slot of synchronous hybrid machine's depth is twice as that of conventional machine.

\subsection{Technique of Enhancing $X_{d} / X_{q}$ Ratio}

The enhancement of $X_{d} / X_{q}$ ratio of the conventional reluctance machine is through the manipulation of the rotor geometry [14, 18 and 21], while in the synchronous hybrid machine, the enhancement of the $\mathrm{X}_{\mathrm{d}} / \mathrm{X}_{\mathrm{q}}$ ratio for a fixed rotor geometry is achieved by using $\mathrm{d}-\mathrm{q}$ analytical method. Here the quadrature axis reactance $X_{q}$ is modified by the capacitance load on the auxiliary circuit while the $X_{d} /$ remains unaffected.

\subsection{Output Power}

The output power of the conventional machine is known to be poor compared to induction machine of the same size, thus putting the reluctance machine into obscurity except for some control applications. The low output power of the conventional reluctance machine accounts for its low $\mathrm{X}_{\mathrm{d}} / \mathrm{X}_{\mathrm{q}}$ ratio. The output power of the synchronous hybrid machine could be increased theoretically without limit because of $X_{d} / X_{q}$ ratio can be anything from zero to infinity. The factor that may limit the output power are the conductor size and effective cooling of the machine assuming negligible resistance in the winding and these apply to all electrical machine.

\subsection{Power Factor Improvement Technique}

In conventional reluctance machine the power factor is improved through the use of shunt or series capacitors. These methods have their relative demerits which made the technique not survive the test of time since the use of shunt capacitors does not lead to a change in maximum output of the machine and the series capacitor will lower the overall impedance of 
the machine resulting in a higher $X_{d} / X_{q}$ ratio. The synchronous hybrid machine unlike the conventional reluctance machine can supply lagging loads as a generator and a leading load as a motor because of its ability to operate in the third and fourth quadrants.

\section{Conclusion}

A hybrid synchronous reluctance machine with an ultra-high $\mathrm{X}_{\mathrm{D}} / \mathrm{X}_{\mathrm{Q}}$ ratio at good power factors has been presented. The new machine is expected to have a relatively better asynchronous characteristic than a conventional synchronous reluctance machine because the difference between the rotor d-axis and qaxis reactances is not so pronounced as in a conventional synchronous reluctance machine. The pull-in torque, as a ratio of the pull-out torque will therefore be greater. The stability of the machine on load can be raised by capacitance tuning after the machine has been brought to synchronism.

The hybrid machine operating from a common busbar and not requiring dc excitation is expected to be a more robust and cheaper machine than the conventional synchronous generator as slip rings and excitation devices and their accessories will be completely eliminated. Absence of rotating windings will permit larger rotor diameter $\mathrm{D}$ which boosts the output power of the machine by a factor of $\mathrm{D}^{2}$. Furthermore, it will permit the use of higher rotor speeds since centrifugal forces on the windings will be completely absent. If the number of poles of a given machine is halved from 4-pole to 2-pole, say, rotor speed as well as the output power will double for a given size of the rotor, resulting in a higher power density.

Consequently, for a given mass of rotor, the axial length of the machine could be shortened and this will eliminate some mechanical problems associated with long axial lengths like sagging and whirling. Additionally, the inertia of the machine will increase and thus improve stability.

The added effects of larger rotor diameter and increased speed can quadruple the output power for a given machine size. The hybrid machine has power factor control, which could be made leading or lagging depending on the tuning of the capacitance loading of the auxiliary winding, a feature that cannot be accomplished in conventional synchronous reluctance machines.

\section{References}

1. A. S. O Ogunjuyigbe, A. A Jimoh, D. V Nicolae and E. S. Obe. 2010 "Analysis of synchronous reluctance machine with magnetically coupled three-phase windings and reactive power compensation". IET Electric Power Applications 2010, Vol.4, Iss. 4, pp. 291-303

2. Anih L U. 'The Performance characteristic of coupled round and salient pole synchronous machines' Ph.D Thesis March 1999.

3. Juha Pyrh“onen, Tapani Jokinen and Val'eria Hrabovcov'a Design of Rotating Electrical Machines 2008 John Wiley \& Sons, Ltd pp. 391380.

4. T. Lipo, "Novel reluctance concepts for variable speed drives," in Mediterranean Electrotechnical conference, MELECON, 1991, pp 34-43.

5. M. J. Kamper and A. F. Volschenk, "Effect of Rotor dimensions cross magnetisation on $\mathrm{Ld}$ and Lq Inductances of Reluctance Synchronous machine with cageless Flux Barrier rotor," IEEE Proceeding- Electrical Power Application, vol. 30, pp. 213-220, 1994

6. I. Boldea, X. Fu, and S. Nasar, "Performance evaluation of axially laminated anisotropic (ALA) rotor reluctance synchronous motors," IEEE Transactions on Industry Applications, vol. 30, pp. 977-985, 1994.

7. F. Parasitili, M. Villani, and A. Tassi, "Dynamic Analysis of synchronous Reluctance motor drives based on Simulink and Finite element model" in IEEE $32^{\text {nd }}$ annual conference on Industrial Electronics, IECON 2006, pp15161520 .

8. A. Vagati, "The synchronous reluctance solution: a new alternative in ac drives," in 20th International conference on industrial electronics, control and instrumentations, IECON'94. vol. 1, 1994, pp. 1-12.

9. E. S Obe and T. Senjyu, "Analysis of a polyphase synchronous reluctance machine with two identical windings," Electric Power System Research vol. 76, pp. 515-524, 2006.

10. L. A Aguand L. U Anih, "A variable $X_{q}$ Synchronous Machine" Proc. Electrical Pow. Engr. Conf (EPEC). UNN, 1997, P.48

11. A. Chiba, T. Fukao, and M. Matsui, "Test Results on a Super High Speed Amorphous Iron 
Reluctance Motor," IEEE Transactions on Industry Applications, vol. 25, pp. 119-125, 1989.

12. T. Matsuo and T. A. Lipo, "Rotor design optimization of synchronous reluctance machine," IEEE Transactions on Energy Conversion, vol. 9, pp. 359-365, 1994.

13. A Vagatti, A. Canova, M. Chiampi, M. Pastorelli, and M Reprtto "Design Refinement of synchronous Reluctance Motor through finite Element Analysis" IEEE transaction on Industrial Application , Vo;. 36 pp 1094-1102 2000

14. I. Boldea, Reluctance Synchronous Machines and Drives. Oxford: Claderon Press, 1996.

15. Lawrenson P. J and Agu L. A, "theory and Performance of Polyphase Reluctance Machine", IEE Proc., vol. 111, No 8, August 1964. Pp 14351445.

16. A. J. O Cruickshank, R. W. Menizes, A. F Anderson, "Axially laminated anisotropic rotors" Proc. IEE, Vol. 13, No. 12, 1966, P. 2058.
17. P. J. Lawrenson and L. A. Agu, "A new unexcited synchronous machine," IEE Proceedings, vol. 110, no. 7, p. 1275, 1963.

18. P. J. Lawrenson and L. A. Agu, "Low-inertia reluctance machines," IEE Proceedings, vol. 111, no. 12, pp. 2017-2025, 1964.

19. P. J. Lawrenson and S. K. Gupta, "Developments in the performance and theory of segmental-rotor reluctance motors," IEE Proceedings, vol. 114, no. 5, pp. 645-653, 1967.

20. S. Williamson, E. R. Laithwaite, "Generalized harmonic analysis for the steady-state performance of sinusoidally-excited cage induction motors" IEE PROCEEDINGS, Vol. 132, Pt. B, No. 3, pp 157-163, MAY 1985

21. W. Fong, "Change-speed reluctance motors," IEE Proceedings, vol. 114, no. 6, pp.797-801, 1967.

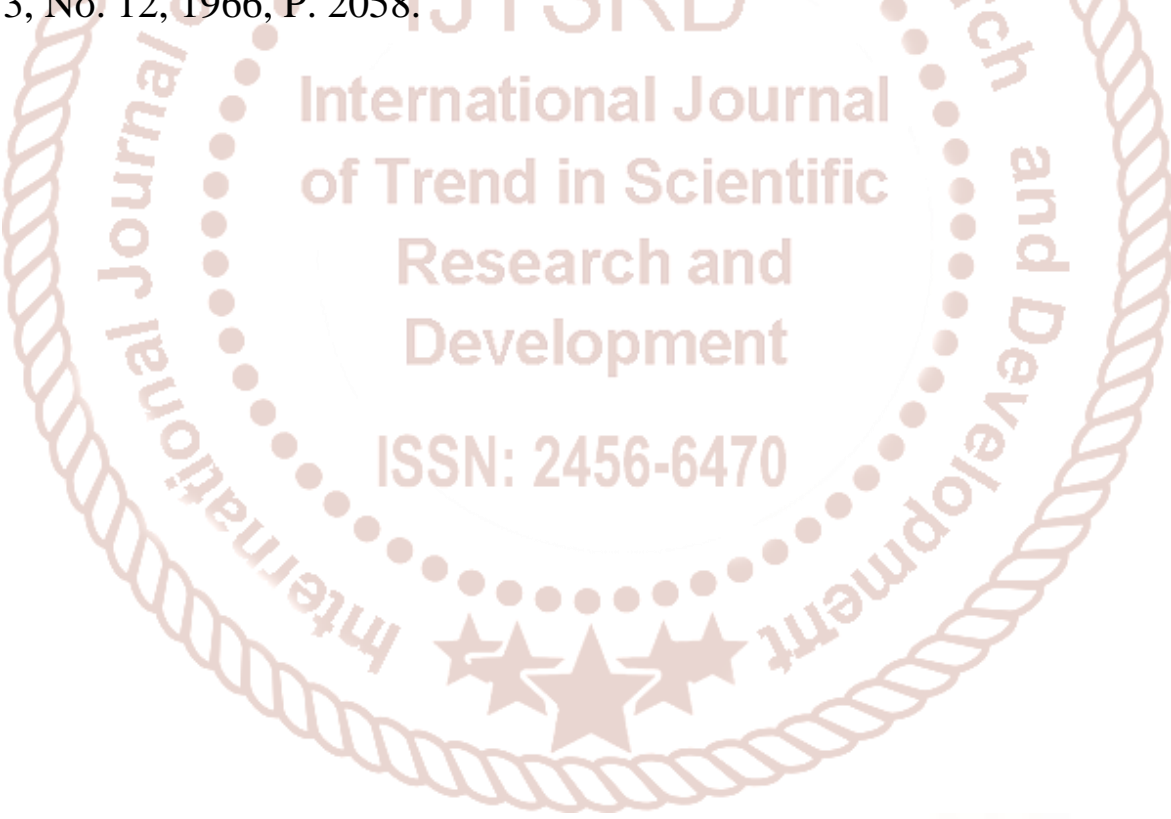

